\title{
159. Order-disorder of Ferric Iron and Aluminum in Ca-rich Clinopyroxene
}

\author{
By Haruo ŌHASHI and Yu HARIYA \\ Department of Geology and Mineralogy, Hokkaido University \\ (Comm. by Seitarô Tsubor, M. J. A., Sept. 12, 1970)
}

Determination of the distribution of cations and the detection of order-disorder phenomena in crystal structure have been obtained from crystal structure analyses by x-ray diffraction method. Recently, Mössbauer spectroscopy provides a rapid method for characterizing the oxidation state, co-ordination number and estimating site populations in iron-bearing minerals. This method has been used to measure the degree of order-disorder between ferrous iron and magnesium in the orthopyroxene series. ${ }^{2)-5)}$

The present study was aimed to investigate the chemical shift and quadrupole splitting with change in electron configuration, oxidation state, and co-ordination symmetry of iron in ferric iron-bearing clinopyroxenes. Measurements of Mössbauer spectra were made at room temperature of five synthetic pyroxenes and one natural pyroxene.

In the diopside structure cations occupy two positions, $\mathrm{M}_{1}$ and $\mathrm{M}_{2}$. The $\mathrm{M}_{2}$ position which is filled by $\mathrm{Ca}^{2+}$ ions is an eight coordination site. The $\mathrm{M}_{1}$ position which is filled by $\mathrm{Mg}$ ions is a six co-ordination site, and $\mathrm{M}_{1}$ octahedron is more distorted in diopside than that in orthopyroxene. Cations in the $\mathrm{M}_{1}$ positions are in octahedral co-ordination with six oxygen ions each linked to one silicon atom. Cations in the $\mathrm{M}_{2}$ positions are surrounded by four oxygen ions which are linked to one silicon atom, and four bridging oxygen ions which are shared by two silicon atoms.

We have synthesized the solid solution of diopside with other iron-bearing compounds such as $\mathrm{NaFeSi}_{2} \mathrm{O}_{6}, \mathrm{CaFe}_{2} \mathrm{SiO}_{6}, \mathrm{CaFeAlSiO}_{6}$ and hematite.

The binary system acmite-diopside has been studied by Yagi (1966) ${ }^{6)}$ At lower temperature there is a complete series of solid solution between the two end members. The Mössbauer spectra of acmite show a simple one line characteristic of $\mathrm{Fe}^{3+}$. This ferric iron must be located at the $\mathrm{M}_{1}$ site in acmite structure which is similar to that of diopside. The solid solutions of acmite-diopside also show the same parameter of Mössbauer spectra as that of acmite end member. 


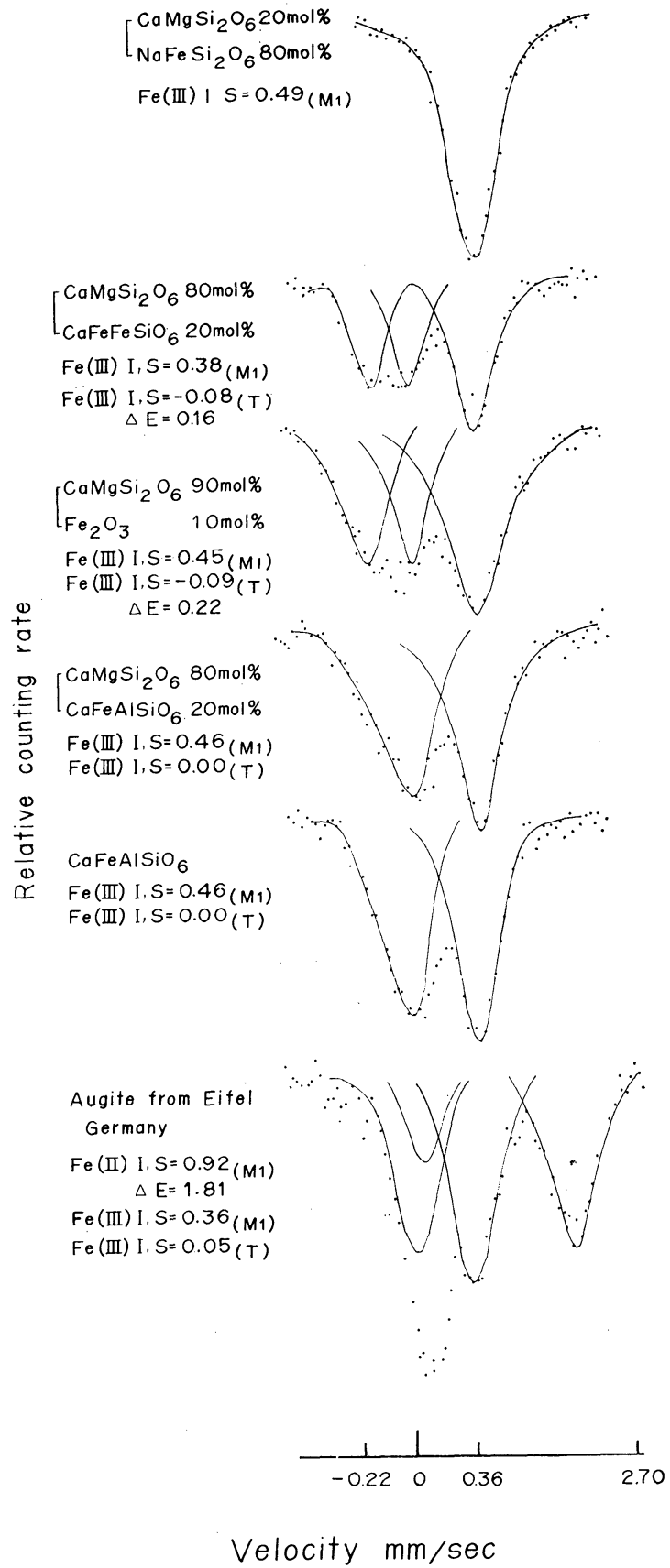

Fig. 1. Mössbauer spectra of ferric iron-bearing clinopyroxene solid solutions.

I.S.: Chemical shift, $\Delta \mathrm{E}$ : Quadrupole splitting, $\mathrm{M}_{1}$ : Octahedral site (six co-ordination), $\mathrm{T}$ : Tetrahedral site (four co-ordination). 
The system of diopside-ferri-Tschermak's molecule has been studied by Huckenholz et al. (1967). ${ }^{7} \quad$ They observed that the maximum degree of solid solution of ferri-Tschermak's molecule in the stable diopside is greater than 31.1 and less than $35.0 \mathrm{wt} \%$ and is believed to be close to $33 \%$ at $1157^{\circ} \mathrm{C}$. We have synthesized the solid

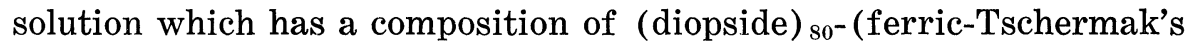
molecule $)_{20}$. The Mössbauer spectra of this clinopyroxene show characteristic peaks of $\mathrm{Fe}^{3+}$ which occupies the different sites, $\mathrm{M}_{1}$ and tetrahedral site. The presence of a ferri-Tschermak's molecule $\mathrm{CaFe}^{3+} \mathrm{Fe}^{3+} \mathrm{SiO}_{6}$ is inferred, in which $\mathrm{Fe}^{3+}$ ions occupy $\mathrm{Mg}$ and $\mathrm{Si}$ sites of the standard diopside structure. The quadrupole splitting gives an information that the symmetry of tetrahedral site is slightly distorted. This may be caused by the interraction between $\mathrm{Fe}^{3+}$ ion in the six co-ordination site and $\mathrm{Fe}^{3+}$ ion in the four co-ordination site.

Segnit $(1951)^{8)}$ studied the incorporation of ferric iron in diopside in the subsolidus region. He reported that a maximum of 10 wt $\% \mathrm{Fe}_{2} \mathrm{O}_{3}$ was present in the diopside. This clinopyroxene solid solution is formed by a reaction of $\mathrm{CaMgSi}_{2} \mathrm{O}_{6}+\mathrm{Fe}_{2} \mathrm{O}_{3} \rightarrow \mathrm{CaFeFeSiO}_{6}$ $+\mathrm{MgSiO}_{3}$. Mössbauer spectra of this clinopyroxene solid solution show a similar pattern which is characteristic to $\mathrm{Fe}^{3+}$ of octahedral and tetrahedral sites in that of the diopside-ferri-Tschermak's solid solution.

Clinopyroxene of $\mathrm{CaFeAlSiO}_{6}$ composition was synthesized by Hijikata and the phase diagram for the $\mathrm{CaMgSi}_{2} \mathrm{O}_{6}-\mathrm{CaFeAlSiO}_{6}$ has been determined in air by Hijikata and Onuma (1969).9) The system has complete solid solutions up to $1250^{\circ} \mathrm{C}$. The Mössbauer spectra of $\mathrm{CaFeAISiO}_{6}$ clinopyroxene and solid solution of (diopside $)_{80^{-}}\left(\mathrm{CaFeAlSiO}_{6}\right)_{20}$ shows simple two lines. One of the chemical shift of the $\mathrm{Fe}^{3+}$ in these pyroxenes is closed to $\mathrm{M}_{1}$ position in the acmite. The other shift of the $\mathrm{Fe}^{3^{+}}$must be located at the tetrahedral position of clinopyroxene structure and the chemical shift is close to the four co-ordinated $\mathrm{Fe}^{3^{+}}$in the ferri-Tschermak's molecule. Judging from the Mössbauer spectra the $\mathrm{Fe}^{3+}$ occupies both the $\mathrm{M}_{1}$ octahedral position and tetrahedral position. This phenomenon is related to the order-disorder of $\mathrm{Fe}^{3+}$ and $\mathrm{Al}$. It is estimated that $\mathrm{Fe}^{3+}$ and $\mathrm{Al}$ are included in two sites of six co-ordination and four coordination. So the $\mathrm{CaFeAlSiO}_{6}$ clinopyroxene should be expressed as $\mathrm{Ca}\left(\mathrm{Fe}_{1-x} \mathrm{Al}_{x}\right)\left(\mathrm{Al}_{1-x} \mathrm{Fe}_{x}\right) \mathrm{SiO}_{6}$.

We also measured Mössbauer spectra of natural augite from Eifel, Germany. The chemical composition of this mineral is shown in Table I. The peaks noticed in the Mössbauer spectra of this pyroxene may be assigned as follows: $\mathrm{Fe}^{2^{+}}$ions in the $\mathrm{M}_{1}$ position, $\mathrm{Fe}^{3^{+}}$ions in both the $\mathrm{M}_{1}$ site and four co-ordination tetrahedral site. 
Table I. Chemical analysis of augite from apatite-magnetite-clinopyroxenite ${ }^{1)}$

\begin{tabular}{l|c} 
& (Eifel, Germany) \\
\hline $\mathrm{SiO}_{2}$ & wt\% \\
$\mathrm{Al}_{2} \mathrm{O}_{3}$ & 46.20 \\
$\mathrm{TiO}_{2}$ & 7.38 \\
$\mathrm{Fe}_{2} \mathrm{O}_{3}$ & 1.70 \\
$\mathrm{FeO}$ & 6.94 \\
$\mathrm{MnO}$ & 5.97 \\
$\mathrm{MgO}$ & 0.26 \\
$\mathrm{CaO}$ & 8.96 \\
$\mathrm{Na}_{2} \mathrm{O}$ & 19.85 \\
$\mathrm{~K}_{2} \mathrm{O}$ & 1.91 \\
$\mathrm{H}_{2} \mathrm{O}$ & 0.06 \\
$\mathrm{Total}$ & 0.67 \\
\hline
\end{tabular}

*) The total is given as 99.86 in the original paper.

The $\mathrm{Fe}^{3+}$ and $\mathrm{Al}$ exchange between the octahedral sites and tetrahedral sites in clinopyroxenes has been recognized in natural and synthetic pyroxenes. The detection of order-disorder phenomena in these pyroxenes may provide a potential means of determining the temperature and pressure of formation of these minerals.

The writers wish to express their sincere thanks to Professor S. Tsuboi, M. J. A., and Professor K. Yagi for the critical reading of the manuscript, and to Dr. K. Aoki for the gift of the augite from Eifel. The authors also wish to thank Mr. Y. Fujio for Mössbauer analyses.

\section{References}

1) Aoki, K., and Kushiro, I. (1968): Contr. Miner. and Petr., 18, 326-337.

2) Bancroft, G. M., and Burns, R. G. (1967): Earth and Planetary Sci. Letters, $3,125-127$.

3) Bancroft, G. M., Burns, R. G., and Howie, R. A. (1967) : Nature, 213, 12211223.

4) Dundon, R. W., and Walter, L. S. (1967): Earth and Planetary Sci. Letters, 2, 372-376.

5) Evans, B. J., Ghose, S., and Hafner, S., (1967): Jour. Geol., 75, 306-322.

6) Yagi, K. (1966): Amer. Miner., 51, 976-1000.

7) Huckenholz, H. G., Schairer, J. F., and Yoder, H. S., Jr. (1968): Yb. Carnegie Inst. Wash., 66, 336-341.

8) Segnit, E. R. (1951) : Miner. Mag., 30, 218-226.

9) Hijikata, K., and Onuma, K. (1969): Jour. Japan. Assoc. Min. Petr. Econ. Geol., 62, 209-217. 